Elsevier required licence: (C) <2017>. This manuscript version is made available under the CC-BY-NC-ND 4.0 license http://creativecommons.org/licenses/bync-nd/4.0/ 


\section{The impact of society on management control systems}

Jan Greve, Örebro University, Sweden *

Christian Ax, University of Gothenburg, Sweden

David S. Bedford, University of Technology Sydney, Australia

Piotr Bednarek, Wrocław University of Economics, Poland

Rolf Brühl, ESCP Europe, Germany

Johan Dergård, Lund University, Sweden

Angelo Ditillo, Università Bocconi, Italy

Andrea Dossi, Università Bocconi, Italy

Maurice Gosselin, Université Laval, Canada

Sophie Hoozée, Ghent University, Belgium

Poul Israelsen, Aalborg University, Denmark

Otto Janschek, University of Economics and Business, Vienna, Austria

Daniel Johanson, Norwegian School of Economics, Norway

Tobias Johansson, Karlstad University and Örebro University, Sweden

Dag Øivind Madsen, University College of Southeast Norway, Norway

Teemu Malmi, Aalto University, Finland

Carsten Rohde, Copenhagen Business School, Denmark

Mikko Sandelin, Aalto University, Finland

Torkel Strömsten, Stockholm School of Economics, Sweden

Thomas Toldbod, Aalborg University, Denmark

Jeanette Willert, Copenhagen Business School, Denmark

* Corresponding author. Email: jan.greve@oru.se; Tel.: +4619 303767

Acknowledgements

We would like to thank Frank Selto for comments and suggestions on an earlier version of the paper at the Manufacturing Accounting Research conference in Copenhagen, Denmark, in 2014 and Patrik Tran for his comments on a more recent version presented at the Nordic Workshop in Management Accounting in Visby, Sweden, in 2017. We also want to thank two anonymous reviewers for helpful comments and suggestions. We are grateful for financial assistance and support provided by Jan Wallanders \& Tom Hedelius Stiftelse and Tore Browalds Stiftelse at Svenska Handelsbanken. 


\begin{abstract}
The aim of this study is to investigate whether certain types of management control systems (MCSs) dominate in certain societies (socio-cultural contexts) and whether the effectiveness of a given type of MCS varies depending on the socio-cultural setting - the society - in which it operates. The study focuses on three socio-cultural groups and the corresponding institutional contexts (an Anglo-Saxon group, a Central European group, and a Northern European group) and three MCS styles, or types (delegated bureaucratic control, delegated output control, and programmable output control). We use unique data from a cross-national, interview-based survey encompassing 610 strategic business units from nine countries (seven European countries plus Canada and Australia). The idea that firms tend to adapt MCSs to the socio-cultural context does not gain empirical support in this study. No significant differences in the distribution of MCSs between the three socio-cultural groups are noted. However, we do find that programmable output control has a more positive impact on effectiveness in Anglo-Saxon cultures, while delegated output control has a more positive impact on effectiveness in Northern Europe. Taken together these findings indicate that distinct differences between societies make a particular MCS design more appropriate in a given society, but where such differences are not dramatic (as in the present case), multiple MCS designs can be found in the same society.
\end{abstract}




\section{Introduction}

What explains the design and use of management control systems (MCSs)? This question is fundamental to management control scholars and has generated an impressive body of knowledge (Chenhall, 2003). Empirical researchers have focused largely on how various contingency factors interact with MCSs, while less attention has been paid to the institutional contexts in which these interactions take place. Generally, the question pertaining to how the design and use of MCSs, and their effectiveness, may be influenced by the institutional contexts in which they operate is rarely addressed by contingency scholars. This is surprising considering that the central point of the contingency framework is the importance of context in understanding the design, use, and effectiveness of MCSs. This implies that observed relationships between contingencies and MCSs are presented as universally valid across institutional contexts, a circumstance that ought to spur contingency researchers within the MCS literature to think differently. Moreover, the lack of attention to institutional context may help explain the somewhat inconclusive results that have been reported in this stream of studies.

This outlook is supported by insights from a critical examination of perspectives used to explore the basis of differences in cross-country MCSs. Bhimani (1999) compares the conventional contingency theory perspective with four alternative perspectives: 'the culturist perspective', from which nationally rooted cultural forces are seen as developing nationally specific solutions to control problems; 'the business system perspective', ${ }^{1}$ from which MCSs are seen as embedded in societal institutions; 'the new institutionalism perspective', from which MCSs are seen as reproduced and reflecting taken-for-granted practices; and 'the "new" history perspective', from which contemporary MCSs are seen as reflecting historical political, socio-cultural, and economic changes. The study notes that the contingency perspective's reliance on "universalism and functionalism" (p. 434) is problematic because there are convincing arguments that the impact of conventional contingency factors on MCSs as revealed in cross-country research is restricted or even eliminated by socio-cultural or institutional factors (see Bhimani (2007) for an overview of the literature).

In this study we follow the lead of Whitley (1999a), who adopts the business systems framework (see also, e.g., Maurice, 1979; Sorge, 1991; Sorge \& Maurice, 1993; Sorge \& Warner,

1 Bhimani (1999) terms this research track "societal effects" but in the present paper we refer to it as the "business system" framework because this is the concept most frequently used in the literature (Maurice, 1979; Sorge, 1991; Sorge \& Maurice, 1993; Sorge \& Warner, 1986; Whitley, 1992). 
1986; Whitley, 1992) to explain the existence and effectiveness of various types of MCSs within various business systems. ${ }^{2}$ According to this framework, the conditions that enable actors to engage in economic activities are explained by their societal or socio-cultural context, i.e., a combination of value-based institutions (such as socio-cultural ideas and attitudes about trust, authority, loyalty, or individual rights) and proximate societal institutions (such as capital markets, education systems, and trade unions). Together these institutions shape, and are influenced by, the business system in a society (Whitley, 1992). Because institutions, and hence business systems, vary between societies, firms face varying conditions from one society to another and therefore behave differently depending on the society in which they operate. These explanations of organizational behavior and design parallel arguments from transaction cost economics (North, 1991; Williamson, 1998) which, apart from the link between transaction characteristics and governance structure, is also a theory of the comparative efficiency of governance structures (market, hybrid, and hierarchy) under varying institutional conditions (rules of the game). In contrast to the transaction cost framework, however, business systems theory also more thoroughly examines both the industry and organizational levels. This makes it possible to adapt the framework to an MCS point of view since societal institutions are not only linked to contingencies (such as uncertainty) but also to administrative arrangements such as planning, performance measurement, and work organization. For example, managers delegate responsibility because they trust in a society's rules and procedures (societal institutions) but also because they trust employee skills (which depend on public training systems), the relative power of employees (which depends on the strength of unions), and a willingness to share risks (which is indirectly influenced by the way in which business finance is organized in a given society).

The number and complexity of factors that constitute this framework may initially seem overwhelming, but because many factors are thought to be interdependent and/or complementary, only a limited number of societal configurations appear in empirical research - in terms of in-

2 The business system framework has been used for analysis of firm-level and management characteristics in individual countries (e.g., Halvorsen et al., 1996; Lilja \& Taino, 1996) and sectors/regions (e.g., Räsänen \& Whipp, 1992; van Iterson, 1996) as well as for comparative studies between countries (e.g., Lane, 1997; Sorge \& Warner, 1986). It has also been applied in studies of the development of innovative competencies (Casper and Whitley, 2004; Whitley, 2000, 2002), corporate governance (e.g., Hartzing \& Sorge, 2003), and globalization and organizational change (Kristensen \& Morgan, 2012; Lane, 2006; Morgan, 2009). 
stitutional arrangements, i.e. types of societies and MCSs (Whitley, 1999a, 1999b). A configurative approach to this issue has the potential to add to our knowledge of interactions between institutions at the societal level and MCSs at the organizational level. Such an approach responds to calls in the literature for more accounting research applying a configurative approach (e.g. Chenhall \& Langfield-Smith, 1998; Bedford \& Malmi, 2015).

Whitley's article (1999a) is conceptual and his propositions pertaining to relationships between societies and MCSs are tentative. Departing from Whitley, we elaborate on the classification of MCSs in a way that is more in line with common typologies of MCSs used in the accounting literature. Furthermore, because neither strong theory nor a deep understanding of empirical circumstances exists regarding exactly how institutional context and MCSs interact, we develop hypotheses related to both the congruence and the contingency structural form of fit between institutional contexts and MCSs (Gerdin \& Greve, 2004). Departing from Whitley (1999a), and using studies on empirical classifications of countries into types of society (Hotho, 2014), we test hypotheses about whether certain types of MCSs dominate in certain societal types and/or whether MCSs differ in effectiveness across societies.

Using a cross-country data set covering 610 strategic business units, we show that MCSs vary in effectiveness (measured by return on assets-ROA) with the socio-cultural contexts in which they operate. To the best of our knowledge we offer the first large-scale empirical evidence of the importance of society-MCS fit and as such we add important knowledge to the contingencybased literature on MCS design and use (Hartmann, 2000; Chenhall, 2003; Gerdin \& Greve, 2004). Our hypotheses related to the domination of certain types of MCS in certain societies find no support, which seems logical considering that the presence of the contingency form of fit decreases the likelihood of finding evidence of the congruence form (Gerdin \& Greve, 2004). Our findings thus imply that in today's business system landscape MCSs travel and become established widely in organizations across societies (Granlund \& Lukka, 1998). Still, the appropriateness of such MCSs when implemented across societies varies significantly. Such a finding should not only contribute to scholarly knowledge but also be practically relevant to managers and consultants.

The remainder of this study is organized as follows. The next section presents a taxonomy of societies or socio-cultural contexts (derived from the business system framework) followed by a discussion of society as a contingency factor. Special attention is dedicated to possible adaptation behavior and to various forms of fit. Thereafter, we extend Whitley's typology of MCSs 
and derive hypotheses. Section 3 presents the data collection procedure, the measurement of variables, and the statistical methods used for testing the hypotheses. The results of the statistical analysis are presented in Section 4. The final section discusses the results, presents the research contributions of the study, highlights limitations, and, finally, provides some suggestions for further research.

\section{Theory}

\subsection{Society as a contingency factor}

Whitley maintains that institutions vary from one society to another. Institutions influence organizations and decision-making, while organizational features in turn are closely linked with MCS characteristics. He lists six institutional factors that combine to form institutional contexts and suggests a typology containing six generic types of societal configurations (Whitley, 1999a, 1999b) The validity of the typology has been empirically tested with data from 30 OECD countries for the years 2000-2011, as reported by Hotho (2014). ${ }^{3}$ Generally, Hotho's study confirms the empirical existence of four of the six societal types suggested by Whitley (1999b), but it also identifies a type not previously discussed. Reflecting the availability of data, the present study focuses on MCSs in two of the societal types presented in Whitley (1999b) and the novel type added by Hotho (2014). The three types are presented in Table 1.

Table 1 about here

The labels and attributes of the two first types are based on Whitley's (1999b) typology while the attributes of the "new" type come from Hotho (2014). When Whitley (1999a) discusses MCSs he refers to institutions as geographic areas. The Anglo-Saxon group is represented by

3 In literature "typology" is frequently defined as a set of conceptually derived configurations. They may be ideals that do not exist empirically and any attempt to validate them empirically is thus dubious (Doty \& Glick, 1994). Whitley conceive societal types as "reference points against which empirical economies can be compared and deviations explored" (Whitley, 2006, p. 1163). Hence, he understands types as idealized descriptions of societies. Henceforth we will use the term "type" when we refer to the idealized descriptions and the terms "cluster" or "group" when we refer to the empirical phenomena. 
type 1 and the Central European group is represented by type 2. The Northern European group is represented by type 3 (Hotho, 2014).

The Anglo-Saxon group is claimed to be relatively capital-market oriented and firms tend to be isolated from other economic actors and from the state. Market regulation and dependence on the state are low, and training systems (education) and unions are relatively weak. This contrasts with the Central European group where firms tend to be embedded in reciprocal relationships with banks, other firms or with sector-specific associations. Markets tend to be more regulated, business depends on the state to a higher extent, and education systems and unions are stronger. According to Hotho (2014), the Northern European group combines strong unions and education systems with liberal features such as low business dependence on the state and minor reliance on market regulations.

Not all types of MCSs are appropriate in all societies (Whitley, 1999a). Hence, a certain type of MCS may be appropriate for one sort of organization that can be found in a particular society but the same MCS is of less value for organizations in other societies. From a contingency theory perspective it can be argued that society represents a contingency factor and that a firm's effectiveness is contingent on how well attributes of its MCS fit with societal institutions. Because institutional factors do not vary on an organizational level, society can explain variations among MCS types only on a societal level. This contrasts with most contingency factors that have been proposed in the accounting literature and where effects have typically been studied at the organizational or sub-unit level (Chenhall, 2003; Luft \& Shields, 2003).

The concept of fit plays a central role in the contingency framework. Theory asserts that in any given situation a certain organizational structure will be optimal, i.e. firms with a particular structure will outperform firms with other structures. Hence, effectiveness is explained by the fit between a specific situation and a firm's structure. It must be stressed that contingency theory makes assumptions only about contextually determined optimal structures; it says nothing about whether firms actually make rational choices or align their structures optimally (Grabner \& Moers, 2013). Hence, it is an open question whether firms actually adapt their structures to specific contexts or whether the optimal structures are more or less randomly distributed among firms. The answer to that question leads to two distinct forms of fit - the congruence form and the contingency form (Gerdin \& Greve, 2004). With reference to the congruence form of fit, firms are generally assumed to adapt structure to context to survive. We should therefore expect 
covariation between context and structure (Drazin \& Van der Ven, 1985; Donaldson, 2001). The economic rationale (explanation) underlying such adaptation processes is that the benefits and costs of MCSs differ with institutional arrangements (Whitley, 1999a; Williamson, 1985, 1998). For various reasons firms may nevertheless maintain controls that do not fit with society. Ignorance of optimal structures may for example be due to time lags, management fashion, or bounded rationality (Abrahamson, 1991; Donaldson, 2001; Johansson, 2015). When no specific type of MCS is clearly dominant in a society, there is little or no opportunity to detect fit by correlating a society with an MCS. Such diversity of MCSs in every society offers, however, another way to model and detect fit. It is now possible to examine whether different types of MCSs differ in effectiveness in different societies. The two forms of fit are both expressions of the same underlying theory (i.e. fit causes effectiveness) but the causal relationships are different (Figure 1).

Figure 1 about here

Under the congruence form of fit, the optimal MCS should depend on societal institutions, in which case effectiveness is not explicitly recognized in the model (although it explains the correlation between society and an MCS theoretically). In a contingency theory model, an optimal MCS in conjunction with a given society increases effectiveness and this effect is explicitly modelled. These forms of fit rely on distinct assumptions about organizational behaviour and it is unlikely that both forms of fit would be discovered in the same empirical setting. They can instead be understood as each other's mirror images - when one form of fit prevails, the other form of fit is rarer (Grabner \& Moers, 2013). They overlap only when 1) most firms in a given society have adapted their MCSs to societal institutions (the congruence form of fit) but 2) a "sufficiently" large group have not adapted their MCSs to society (Luft \& Shields, 2003).

What assumptions should be made about the form of fit in a given societal or socio-cultural setting? From an economic point of view we should expect that firms tend to choose the MCS that is optimal in a certain societal context. If it takes a relatively long time to respond to environmental changes the relationship between context and MCS should be weaker (Donaldson, 2001, Luft \& Shields, 2003), but since most societal institutions evolve relatively slowly over time it seems likely that firms in general have adequate time to adapt their MCSs to society. In 
this case the congruence form of fit is more likely to apply, as suggested by Whitley (1999a). Yet, the congruence form of fit presumes that decision-makers know what an optimal MCS looks like and that they have no incentives to ignore this knowledge (Grabner \& Moers, 2013). Moreover, from a neo-institutional perspective it has been argued that decisions about MCS adoption are driven by isomorphism rather than by economic rationality when decision-makers feel uncertainty about economic consequences (DiMaggio \& Powell, 1983). Under such circumstances we should instead expect a contingency form of fit to apply. This does not necessarily conflict with Whitley's (1999a) central ideas about optimal MCSs in particular societies although it questions his expectations regarding adaptive behaviour. Because theorizing the role of societal institutions for MCS effectiveness is novel, and extensive empirical descriptions about how firms experiment with and adapt their MCSs to institutional contexts are lacking in the literature, we cannot decide a priori what structural form of contingency fit is the most appropriate. Instead we deduce and pose hypotheses about both the congruence and contingency forms of fit.

\subsection{A typology of MCS}

Whitley (1999a) argues that four attributes of MCSs differ considerably across institutional contexts. The first dimension of control — formalism — is understood in terms of quantified, often financial, measures and indicators as well as extensive reliance on codified procedures and rules for monitoring and evaluating performance. The second dimension of control involves the extent to which individual group or organizational unit behavior is prescribed and controlled by superiors - either formally (e.g. by rules and standards) or informally (by personal supervision). The third dimension reflects the degree of subordinates' involvement in processes of control, e.g. target-setting, monitoring, or evaluating performance. Finally, the fourth dimension involves the scope and immediacy of feedback in the control system. Whitley exemplifies this last dimension by comparing the scope of control in stereotypical US and Japanese firms, where the former tend to allocate rewards based on short-term and narrowly defined indicators while the latter take a wider range of aspects of performance into account and also extend the evaluation period over several years.

These dimensions of control are conceptually distinct but not mutually exclusive. For example, extensive use of formal rules may be combined with intensive activity control (as would be the case in a highly bureaucratic organization), but it may also be applied in firms where decisions about work processes have been delegated to subordinates who are being controlled by financial 
results. Likewise, intensive activity control does not necessarily imply a high degree of formality - it may also be practiced in organizations with low degrees of formality, as in small ownercontrolled firms (using personnel supervision). Whitley suggests that these four dimensions can be combined to constitute four distinct types of MCSs, of which three are portrayed in Table 2 below: ${ }^{4}$ bureaucratic control, output control, and delegated control.

Table 2 about here

Bureaucratic control combines formal rules and procedures with a high degree of activity control, low influence of subordinates, and a narrow scope. Output control parallels bureaucratic control with one critical exception - activity control is much weaker, which means that control of activities has been replaced by control of (financial) output. In delegated control the degree of formality varies with firm size (where larger firms apply more formal rules) and subordinates' influence in these control systems is relatively high when compared with other types. Scope is also high in delegated systems.

The bureaucratic type of control is well known in the contingency literature (e.g. Ouchi, 1979, 1980) although the terminology varies somewhat (bureaucracy based control: Van der MeerKoistra \& Vosselman, 2000; rules control: Lebas \& Weigenstein, 1986; machine control/boundary control: Speklé, 2001). Likewise, output control has been frequently applied in the contingency literature (Abernethy \& Brownell, 1997; Eisenhardt, 1985; Govindarajan \& Fisher, 1990; Ouchi, 1977; Rockness \& Shield, 1984; Snell, 1992), although in some typologies it has been termed 'results control' (e.g. Emmanuel et al., 1996; Merchant \& Van der Stede, 2013) or 'market control' (Lebas \& Weigenstein, 1986; Ouchi, 1979, 1980; Speklé, 2001). Generally, bureaucratic control and output control have been defined as highly formalized control systems with high and low degrees of activity control, respectively. So far, the two types of control

4 The fourth type in Whitley's (1999a) typology is denoted as patriarchal control. Since this type of control is not claimed to appear in any of the societies being investigated in the present study we do not review patriarchal control. 
conform to the types suggested by Whitley. When it comes to subordinates' influence and organizational scope, the contingency literature offers a more complex picture (compared with Whitley (1999), where influence and scope generally are claimed to be low).

Influence and scope in bureaucratic control has been discussed from various viewpoints. Merchant and Van der Stede (2013) note that action control can be either tight or loose and they list various forms of "soft" action controls such as behavioural constraints (i.e. physical or administrative barriers) and accountability (communicating with and holding subordinates responsible for their actions). Speklé (2001) distinguishes between two types of hierarchical control: machine control (action control through predefined actions) and hierarchical boundary control (stipulation of unacceptable actions). While machine control resembles Whitley's conception of bureaucratic control, boundary control represents a bureaucratic type of control wherein subordinates have considerable influence on the formulation of tasks and the evaluation of outcomes (ibid, p. 435). Adler \& Borys (1996) distinguish between coercive and enabling formalization in bureaucratic control. Coercive formalization is top-down oriented, rules are used to limit the initiatives of employees, and deviations from standards are generally regarded with suspicion. This opposes enabling formalization, where rules aim to help employees complete their tasks, and where dialogues between superiors and subordinates are welcomed to improve the transformation process.

Similarly, business control has regularly been discussed from a delegation perspective. Subordinates' ability to influence a control system has been a central topic in the RAPM literature (Hartmann, 2000), the budget participation literature (Shields \& Shields, 1998), and the "tight budgeting" literature (e.g. Van der Stede, 2001). For example, while tight budget control stresses budget goals and shows little tolerance of budget deviations or revisions, a budget system characterized by loose control represents a more relaxed form of output control. In such a system subordinates may influence budget objectives, changes in budget conditions are countered with budget revisions, and a negative deviance from a budget is not necessarily perceived as an indication of poor performance (Anthony \& Govindarajan, 1995).

In summary—while Whitley (1999) contrasts delegated control with the two top-down-oriented types, bureaucratic control and output control, it is recognized in the contingency literature that delegation may be effectively combined with bureaucratic or output control. The two standpoints do not really conflict. The delegated control type in Whitley's (1995a) typology “grants 
considerable autonomy to subordinate groups and units over work performances and may also involve them in standard setting and monitoring" (ibid p 511), i.e. it resembles the loose form of output control. Whitley also admits that bureaucratic control, when practiced, does not constrain superiors very strictly by rules and that "the extent of control over the work process is much less, with more discretion being granted to subordinates" (ibid p 519). In light of these observations, we propose a modified MCS typology that relates to findings in the contingency literature where it has been argued that delegated forms of control can be combined effectively with bureaucratic or output control (Table 3).

Table 3 about here

Two types of control, programmable bureaucratic control and programmable output control, are identical with bureaucratic and output control in Whitley's typology (table 2). Delegated bureaucratic control combines high degrees of formalization and activity control (bureaucratic control) with a medium degree of influence and broad scope (delegated control). Likewise, in delegated output control, high formality and a low level of activity control (output control) are combined with medium influence and broad scope (delegated control). This profile is almost identical to the profile of delegated control in Whitley's typology - the two profiles differ only on the extent to which they rely on formal rules. In Whitley's delegated control category, the level of formalism is "mixed", which means less formality in "fairly small and specialized" organizations and more formality in large organizations (Whitley, 1999a).

\subsection{Development of hypotheses}

Whitley (1999a) argues that at least six major features of organizations' institutional contexts (see Table 1) are likely to directly affect the sort of control systems they develop. He also discusses several other characteristics related to work organization and firm type that are likely to influence a firm's choice of controls. However, and as Whitley suggests, institutional contexts directly affect the controls firms develop. This study focuses on the impact of these features of institutional contexts. 
According to Whitley (1999b) and Hotho (2014) all the societies included in this study (see Table 1) feature a high level of trust in formal institutions and procedures. Similarly, the reliance on contractual authority relations is strong. The extent to which economic actors feel able to rely on formal procedures and institutions in making commitments to business partners and ensuring their competence affects their willingness to delegate control to intermediates and rely on procedural measures to control behavior (Whitley, 1999a, p. 515-516). As Whitley states (p. 509), these socio-cultural factors are often implicitly contrasted with direct personal control over work activities and reliance on personal, ad hoc, diffuse, and tacit evaluations of performance. Hence, we would expect a high degree of formalization to characterize control systems in societies where economic activities and their assessment are governed largely by impersonal regulations. Because the societies under examination are characterized by high trust in formal institutions and strong reliance on contractual authority relations, we propose that effective MCSs in the three societies generally feature a high degree of formalization. We will now utilize Whitley's framework when we propose how societal institutions (listed in table 1) that differ across the three societies influence the effectiveness of controls (listed in table 2). We start with the Anglo-Saxon group.

As shown in Table 1, the Anglo-Saxon group features a low degree of dependence on the state and weak formal state regulation of markets. Whitley proposes that both factors influence the effectiveness of activity control in an MCS. Where business dependence on the state is heavy, as in South Korea, which implies high political risk, firms are likely to be highly centralized and to exert considerable control over the behavior of subunits. He continues: "Overall, then, strong state involvement in the economy and in firms' strategic choices is likely to encourage the use of top-down, prescriptive control systems" (Whitley 1999a, p. 517). This would imply that where dependence on the state is light, such as in Anglo-Saxon countries, there is less of a need to be prescriptive. Control can be applied at arm's length and focused on outcomes, unless other task- or firm-related characteristics pose other requirements, and the discretion to decide on the details of activities can be left to subunits and subordinates. The relatively weak formal state regulation of markets in Anglo-Saxon societies adds to this effect. Whitley argues that the heavier such regulations are the more we should expect firms to institutionalize formal control systems in their own organizations. A little formal state regulation would mean less prescriptive use of controls within organizations. Therefore, as a result of a low degree of dependence on the state and little formal regulation of markets, we should expect control systems in AngloSaxon countries to have relatively little emphasis on activities. 
Whitley (1999a, p.517) summarizes the specific features of the labor system in various countries, which directly impinge on the influence of subordinates in control systems. Features of labor systems are described along two dimensions: a) the overall strength of public training systems and the extent of union-employer collaboration in their operation, and b) the collective strength of unions and horizontal interest groups - such as professional associations - in general. A strong public training system, involving employers and unions collaborating with the state, is assumed to produce skills that are highly valued by both employees and employers, encouraging firms to trust the competence of their skilled workers. In such societies, managers are less likely to exercise tight control over employee behavior and are more willing to give employees a role in the operation of the control system. Relatedly, strong unions and horizontal interest groups in general will limit the ability of managers to impose tight controls over worker behavior and also encourage them to share some degree of influence over standard-setting and performance evaluation (p. 518). Whitley refers to Germany as a country with a strong public training system. In Anglo-Saxon countries, both public training systems and unions are assumed be weak relative to those in Central or Northern European countries (Table 1). Therefore, we should not expect to find strong influence of subordinates on control systems in AngloSaxon countries.

Whitley (1999a, p. 510) argues that the scope and immediacy of feedback and control mechanisms reflect, among other things, more general features of employment systems, labor markets, and financial systems. He suggests that the stereotypical US corporation tends to focus on relatively short-term and narrowly specified indicators of performance in making career decisions and allocating rewards. This clearly suggests a narrow scope for control systems in AngloSaxon countries.

To summarize, control systems in Anglo-Saxon countries are assumed to be formalized, to place relatively low emphasis on activities, to allow only limited influence by subordinates, and to be narrow in scope. These features correspond to the ideal type of programmable output control. Hence, we predict that the programmable output control type is particularly compatible with, or fit for, the Anglo-Saxon institutional setting. We regard Whitley's and our developed typology of MCSs as ideal types rather than empirical taxonomies. As such we are interested in a firm's empirical adherence to, or resemblance with, ideal types of MCSs (Doty, Glick \& 
Huber, 1993; Doty \& Glick, 1994). As developed above in this article, we can neither theoretically nor empirically specify exactly how the selection of firms' MCS choices related to institutional settings plays out, so instead we propose hypotheses about both domination (congruence) and the performance implications of fit (contingency). Regarding MCS type in the Anglo Saxon group, we pose the following hypotheses:

$\mathrm{H} 1_{\text {congruence: Programmable output control is more dominating in the Anglo-Saxon group }}$ than in the two other groups.

or

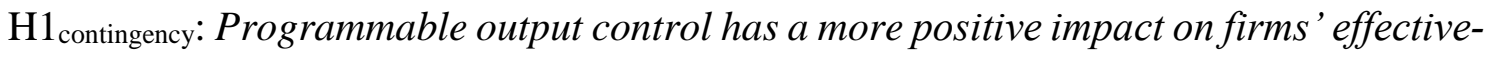
ness in the Anglo Saxon group than in the two other groups.

Business dependence on the state and the extent of market regulations are thought to be higher in central Europe than in other societal groups (Table 1). This may explain why reliance on activity control in MCSs differs between these societies. As discussed above, state dependence would seem to imply that firms are relatively highly centralized and exert considerable control over the behavior of subunits. While it is not clearly obvious that firms are considerably more dependent on the state in the Central Europe group than, say, in the Northern Europe group, Whitley suggests other reasons that might induce Central European firms to rely on activity controls. When major shareholders and creditors are locked into the fate of individual enterprises, as in bank-driven financial markets, they are likely to insist on both formal procedures governing major decisions and frequent flows of both formal and informal information to manage the greater risks involved (Whitley 1999a, p. 514). This would also mean less discretion exercised by top management over strategic choices compared with societies where such a lockin effect is less prevalent. More regulation of markets (e.g. elaborate licensing rules, ibid. p. 514) also drives firms in Central Europe to institutionalize formal control systems in their own organizations. It is evident that instituting more such rules requires more controls pertaining to boundaries to ensure that units adequately adhere to these norms. Hence, we would expect firms in bank-driven and state-regulated Central European countries to rely more heavily on activity controls than their counterparts in Anglo-Saxon and Northern European countries.

Whitley also suggests that firm interdependence with investors and managers in bank-driven financial markets leads to the development of more elaborate and wide-ranging control systems 
in most firms, as planning and control can be more long-term oriented and assume a greater degree of risk-sharing (p. 515). Hence, we would expect the scope of control systems to be high in Central Europe.

As noted above, Whitley (1999a, p. 517) uses Germany as an example of a country where the public training system is strong. As Table 1 suggests, unions also exert strong influence on labor relations in Central Europe. Following the above argumentation, these features should lead to a delegated form of control wherein subordinates have some influence in target-setting and performance evaluation.

To summarize, control systems in Central European countries are assumed to be formalized, to have relatively strong emphasis on activities, to allow for some influence by subordinates, and to be broad in scope. These features correspond with the ideal type of delegated bureaucratic control. Therefore we propose the following hypotheses:

$\mathrm{H} 2$ congruence: Delegated bureaucratic control is more dominating in the Central European group than in the two other groups.

$\underline{\text { or }}$

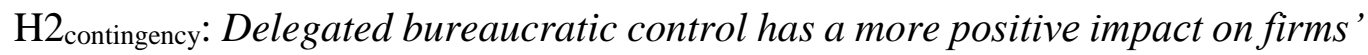
effectiveness in the Central European group than in the two other groups.

Whitley (1999a) does not distinguish between control systems in the Central and Northern European groups. However, as noted by Hotho (2014), there are some notable differences between the two groups. Central European countries are oriented towards bank credits, while Northern European countries are more capital-market oriented. The tendency to rely on bank credits rather than capital markets in Central Europe locks majority-owners and creditors into the fate of a business. Because they cannot easily escape from their commitments, they cope with the high risks involved by frequently asking for information and insisting on formal procedures for strategic decision-making. Demands placed on formalism in corporate governance echoes within an organization as managers try to control activities at lower levels in a corresponding way (Whitley, 1999a). Adopting a capital-market orientation in Northern Europe affects the organization of activities in a direction that aligns with business systems in Anglo-Saxon economies, 
as the lock-in effects for owners are reduced. Still, strong unions and strong training systems in this group make firms less likely to adopt programmable output systems. There will be a pressure from employees and interest from managers not only to delegate operational decisions but also to involve subordinates in control processes, thereby taking full advantage of subordinates' skills and willingness to assume responsibility. This is why we should expect firms in the Northern countries to favor delegated control systems. Based on these arguments we pose the following hypotheses:

$\mathrm{H} 3_{\text {congruence: Delegated output control is more dominating in the Northern European }}$ group than in the two other groups.

or

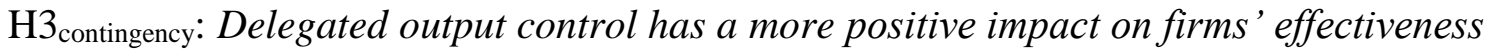
in the Northern European group than in the two other groups.

Programmable bureaucratic control is not expected to dominate or outperform other types of control in any of the three societies being investigated and therefore we will not, hereafter, pay attention to this type of control. The omission of programmable bureaucratic control is in accordance with Whitley (1995a), as he argues that bureaucratic control may be effective in contemporary societies only under very special circumstances.

\section{Research method}

This study is part of a larger international research project focusing on MCS packages. Researchers from nine European countries (Austria, Belgium, Denmark, Finland, Germany, Italy, Norway, Poland, and Sweden), Australia, and Canada participate in the project. The research project consists of several subprojects and the study reported in this paper is one of these subprojects. Data were collected through a structured questionnaire and all participating countries used the same questionnaire (Schaffer \& Riordan, 2003). The questionnaire was based on the framework of Malmi and Brown (2008) and was organized around seven sections: strategic 
planning, short-term planning, performance measurement, incentive system, organizational structure and culture, organizational characteristics, and organizational environment. However, questions of relevance to this study constituted only a minor part of the questionnaire.

Our research focuses on strategic business units (SBU) and the intended respondents are CEOs and managing directors (see Table 4 for numbers and positions of respondents). We defined an SBU as an entity that faces a unique competitive situation (in relation to other corporate units) and can be regarded as having its own competitive strategy. Strategy formulation and implementation can differ at the firm and SBU levels (Govindarajan \& Gupta, 1985), especially in companies with diverse product portfolios. Yet, SBUs within a given company may face marked, specific competitive and contextual factors, so studying SBUs can yield a more homogeneous picture of management control practices than studying practices at the firm level (Kruis et al., 2016). Consequently, we focus on the SBU level to include the effects that varying contexts within SBUs have on SBUs top managers' use of MSCs to affect employee behaviour.

To ensure the reliability of the measurement instruments, regular meetings were arranged for project members to address research design, methodology, and method. A detailed survey manual (providing construct clarification) was developed that explains and underpins the questions in the questionnaire and coding procedures were applied uniformly. Checks on data consistency and missing values were conducted at the local team level.

Even though this project was carried out using a survey, the data were collected via personal interviews with one or more members of the top management teams of each SBU. Researchers, doctoral students, and master's students conducted the interviews. Researchers and doctoral students are members of the core team but the master's students were not. To ensure that they were prepared to conduct the interviews, researchers in the core team educated them, and they had access to a detailed survey manual and a contact person (i.e. one of the researchers on the core team). The time used for an interview was typically between 1.5 and 3 hours. Most responses were given on a 7-graded Likert scale and the remaining responses were chosen from a list of categories (e.g. ownership type).

The ORBIS database was used to select companies from the nine European countries, the Dun and Bradstreet database was used for Australia, and Scott's National database was used for Canada. The ORBIS database contains information on over 200 million companies worldwide and 
more than 93 million companies are situated in Europe. It includes information about geographical region, financials and financial strength indicators, industry, size, stock data, identifiers, etc. The same four factors were used to select the populations from all three databases (Boolean search);

- Status (active)

- Legal forms (private, for-profit companies)

- World region (i.e. country)

- Company size (company size>250 employees).

The lists were then checked manually to avoid duplication and identify companies that were closed or sold, all of which were deleted. From this quality-controlled total list, a random sample was selected (either by random numbers or by selection of 'every third firm'; Cochran, 1977). For each country the sample displays the same distribution for the manufacturing, trade, and services sectors, respectively, as in the total list per country. Finally, from each company an SBU (with 50 or more employees) was selected for questioning (for some companies the SBU coincides with the company). The current study includes nine countries (Italy and Poland do not belong to any of the three institutional groups being examined and were excluded) and the total sample amounts to 694 SBUs, of which 610 were considered usable (Table 4). The sizeable loss of answers was due mainly to insufficient information about capital (assets) or operating profits (effectiveness (see section 3.2) is measured as the average ROA for two years). For some SBUs it was not possible to obtain formal economic reports on capital or operating profits, while some SBUs submitted incomplete reports.

Table 4 about here

\subsection{Variable measurements}

\subsubsection{Dependent variable: Effectiveness}

ROA, based on reported operating profits and reported assets for the two previous years, were calculated and the mean value was assessed. Eleven SBUs reported profits and assets for only one year-usually because the unit did not exist in the other year (due to a merger, bankruptcy, restructuring, etc.). For those SBUs, ROA was based on the single year for which figures were available. 


\subsubsection{Independent variables}

\subsubsection{MCS}

The four variables listed by Whitley (1999a) (formalization, activity control, influence, and scope) are used as conceptualizations of MCSs.

Formalization is taken from Whitley (1999a), and is understood as extensive reliance on codified rules and procedures and the application of quantified — often financial—indicators when managers control economic activities. Many firms rely on budgets and the associated codified rules and procedures for formal planning, coordination, and monitoring of economic activities to ensure the achievement of predictable goals. Simons (1995) characterized this type of budget control as the diagnostic use of budgets, and in the present study we operationalize formalization as the extent to which firms use budgets for diagnostic control. We have replaced budgets with the performance measurement system (PMS) for those SBUs (11 cases) that do not use budgets at all. The construct is based on Simons (1995) and Henri (2006) and contains three questions pertaining to the extent to which managers use budgets (or PMSs) for (1) identification of critical performance variables, (2) targeting critical performance variables, and (3) monitoring progress and correcting deviations from preset performance targets (measured with 7graded Likert scales). The questions (related to all variables) are presented in Appendix 1.

Activity control denotes the extent to which "individual group and organizational unit behavior is tightly prescribed and controlled" (Whitley, 1999a, p 510). In the present study all types of MCSs are characterized by highly formalized control systems and we assume that when activity control is practiced in such organizations it tends to be formalized as well. Formalized activity control can take the form of standardization of procedures as in scientific management (Whitley, 1999a) or machine control (Speklé, 2001), but activity control can also imply the specification of unacceptable behavior or the stipulation of boundaries (Merchant \& Van der Stede, 2013; Simons, 1995; Speklé, 2001). Standardization of procedures is not considered an option for any of the three types being examined in the present study (it relates to programmable bureaucratic control, which was excluded from the typology) and thus we delimit activity control to the stipulation of boundaries. Activity control is measured by questions that refer to prior studies that examine the extent of boundaries (Simons, 2005; Widener, 2007). The instrument contained the following eight questions: To what extent does top management (1) use codes of conduct, (2) review plans before action, (3) employ written authorization levels and decision 
rules, (4) sanction known unethical business conduct by subordinates, (5) employ written guidelines that direct or limit opportunity search, (6) communicate risks and activities to be avoided, (7) apply sanctions to subordinates who engage in risks outside organizational policy, and (8) specify minimum requirements for business opportunities (measured with 7-graded Likert scales)? Three items (questions number 2, 5, and 8) were dropped from the final measure of constructs since loadings were below 0.5 in a factor analysis that was performed.

Influence denotes the extent of subunit involvement in target-setting and in monitoring or evaluating performance (Whitley 1999a, p 510). We based our questions on Bogsnes (2009) when measuring how short-term targets are set regarding (1) ends (goals and objectives), and (2) means (ways to achieve the ends) in the focal SBU. Answers range from "Top management sets targets and passes them to subordinates" to "Subordinates set targets autonomously with little, if any, management involvement". Only five alternatives were available. In the final measure of constructs the scale was still 5-graded but the interval was transformed to 1-7.

Scope denotes long-sightedness in performance evaluation. Broad control systems take several aspects of work performance into account when evaluating performance and they do not give priority to short-term quantitative predefined targets. We use three statements (based on Bogsnes (2009) and Simons (2005)) when we measure broadness: SBU management evaluates subordinates' performance by (1) achievements in leadership behavior, (2) actions and activities taken, and (3) individual effort, and we use 7-graded Likert scales.

An explorative factor analysis (Principal Axis Factoring, Varimax rotation) was undertaken. After excluding three items with low loadings (all related to activity control) all items showed loadings above 0.5 and four factors show Eigenvalues above 1.0. A confirmative factor analysis using AMOS was conducted on this final model for the control of attributes. The measurement model of the control attributes modeled as four latent (reflective) variables produces acceptable fit to the data for a large sample (Hair et al., 2010) and all indicators load above 0.5 on their respective factors. The results of the confirmative factor analysis are presented in Appendix 2. Indexes for each variable were calculated as mean values of indicators.

\subsubsection{Institutional context}

The variable institutional context is based on Whitley (1999b) and Hotho (2014). It is a categorical variable containing three institutional contexts: Anglo-Saxon, Central Europe, and Northern Europe. The Anglo-Saxon and Central European contexts were theoretically derived 
and they were originally termed compartmentalized and collaborative systems, respectively (Whitley, 1999b). The Northern European context was empirically derived by Hotho (2014).

The typology of societies has been empirically tested by Hotho (2014) in a cluster analysis. He conducted two analyses - one with data from 2000 and a second with data from 2011. Overall the clusters remain stable over time, i.e. clusters with similar properties are found in both analyses and the grouping of countries is approximately the same. The reported clusters from these analyses enable us to assign individual countries to the three institutional contexts. Consequently, we refer to these results when sorting the nine countries in our sample in three categories:

Anglo-Saxon group: Australia and Canada

Central European group: Austria, Belgium, and Germany

Northern European group: Denmark, Finland, Norway, and Sweden

The analysis is carried out separately for each society where the focal society is denoted as a dummy variable (value $=1$ ) and the rest of the sample represents the reference group (value $=$ $0)$.

\subsubsection{Control variables}

Many have suggested that societal institutions in concert with other contextual factors affect MCSs. Indeed, institutions might affect MCSs directly, but they may also affect the environment in which they operate and thus exert an indirect effect on MCSs. In this study we control for four environmental factors that are well known from the contingency literature (e.g. Gordon \& Miller, 1976, Khandwalla, 1977, Mintzberg, 1983, Chenhall, 2003) and also for industry grouping of SBUs. For environmental factors we used seven-graded Likert scales. Imputation was used when data were missing (28 occurrences). For industry grouping we use dummies.

Environmental dynamism. A dynamic environment is, as opposed to a stable environment, characterized by rapid changes. Our measure of dynamism is based on Miller \& Friesen (1983). Respondents indicated the magnitude of changes they have experienced in the last three years in each of six listed areas that have had a material impact on their business. The six areas are customers, suppliers, competitors, technology, regulations, and the economy. 
Environmental unpredictability. This measure is adapted from Govindarajan (1984). Respondents rate six environmental areas (as above) on a scale from very predictable to very unpredictable.

Environmental heterogeneity refers to environmental complexity and the measure is based on Miller \& Friesen (1983). It is the mean value of the diversity of 1) customer product/service requirements and 2) competitors' strategies and tactics.

Environmental Hostility has frequently been understood as in terms of the intensity of competition (Chenhall, 2003) although regulatory restrictions and labour or material shortages may also represent a serious threat (Miller \& Friesen, 1983). In this paper environmental hostility is the mean value of 1) perceived intensity of competition for main products/services and 2) perceived difficulty in obtaining necessary inputs.

The study also controls for the industry grouping of the SBUs. This variable is included to control for that differences in MCS effectiveness is not just industry effects. Industry grouping refers to manufacturing, services, and trade/wholesale. Dummies are used with manufacturing as reference.

\subsection{Data analysis}

We rely on Whitley's typology when testing the hypotheses and we adopt a configurative perspective. The three MCS types are clearly regarded as control systems and a system approach is thus appropriate for hypothesis tests (Drazin \& Van der Ven, 1985). As a first step the three ideal types (see Table 4) were translated into quantifiable ideal profiles (Table 5).

Table 5 about here

A seven-graded scale was used where "low" was denoted by 1, "limited" by 2 ,"medium" by 4 , "considerable" by 6 and "high" by 7. The dimension "Influence" in Whitley's typology ranges only between "low" and "medium" while the three other dimensions range between "low" and "high". It was not obvious how to interpret this divergence. Is medium the maximum level of influence (i.e. higher levels cannot be reached) or is medium the optimal level and higher levels might harm effectiveness? We decided to translate medium with 4 , thereby suggesting that higher values (i.e. 6-7) reduce effectiveness. 
In a second step the distances between optimal and actual profiles for each case were computed (expressed in terms of Euclidian distance). For example, the Euclidian distance $(E D)$ between one case $(i)$ and the programmable output control type was assessed in the following way:

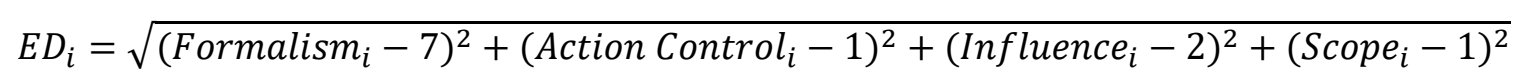

This operation was carried out for each type, meaning that for each case the distance to each of the three types of MCS was calculated. To facilitate the interpretation of results the scales were then reversed, i.e. a high value on the MCS variable indicates proximity to the ideal type of that MCS.

Hypothesized associations were examined by OLS regressions and in a third step models were assessed to complete tests of hypotheses $1-3$. The following regression model was assessed to test congruence hypotheses:

$$
M C S_{i}=a+b_{1} \text { Society }_{j}+b_{2-6}(\text { Controls })
$$

MCS represents proximity to one ideal MCS $(i)$ and society (expressed as a dummy with the value 1) represents one society $(j)$. The model controls for firm-specific features, although we are only interested in the variety at the societal level. The regression was run three times-each time with an MCS and a society that are hypostatized to fit with each other.

The contingency hypotheses were tested with moderated regression analysis (Hartmann \& Moers, 1999) with ROA as the dependent variable and MCS and Society as independent (and interacting) variables:

$$
R O A_{i j}=a+b_{1} M C S_{i}+b_{2} \text { Society }_{j}+b_{3} \text { MCS }_{i} \text { Society }_{j}+b_{4-8} \text { (Controls) }
$$

According to theory, a particular MCS with certain features has a more positive impact on effectiveness in one society than in others. Thus we should expect a positive interaction effect $\left(b_{3}\right)$ on ROA when an MCS fits with a society. This represents a cross-level model with a topdown interaction (Luft \& Shields, 2003, p. 198) 


\section{Results}

Table 6 presents the descriptive statistics for the sample. Variables 2-4 represent the three forms of MCSs and the value measures proximity to the type of MCS, respectively. Variables 5-7 represent societies. They are represented by dummies and are internally dependent (analytically).

Table 6 about here

We tested the congruence form of fit by regressing societies with MCSs. We then tested the contingency form of fit by assessing the effect on ROA of interaction between societies and MCSs. The results from the six regressions are presented in Table 7.

Table 7 about here

It has been suggested that programmable output dominates in Anglo-Saxon societies (H1). Results in Table 7 indicate a significant negative association between society and programmable output $(-0,159)$, suggesting that programmable output control is relatively uncommon in AngloSaxon societies (when compared with Central and Northern European societies). Hypothesis $\mathrm{H} 1_{\text {Congruence }}$ is thus rejected. However, the results also indicate that programmable output control has a significantly more positive influence on effectiveness in Anglo-Saxon society when compared with the two other societies. The interaction effect is positive and significant $(+0,508)$ and hypothesis $\mathrm{H} 1_{\text {Contingency }}$ thus gets support.

Hypothesis $\mathrm{H} 2$ states that delegated bureaucratic control fits with Central European society, but the results presented in table 7 do not confirm this idea. A positive relationship is reported between society and delegated bureaucratic control $(+0.020)$ but it is insignificant and hypothesis $\mathrm{H} 2$ Congruence, which pertains to the congruence form of fit, is thus rejected. The hypothesis that pertains to the contingency form of fit $(\mathrm{H} 2$ Contingency $)$ is also rejected since the interaction effect is negative $(-0.130)$.

Delegated output control is suggested to fit with institutions in Northern Europe (H3). The congruence form of fit does not seem to be apparent - the coefficient is negative (-0.026). Since $\mathrm{H} 3$ Congruence receives no support we reject that hypothesis. However, an interactive form of fit is 
observed. The interaction coefficient between society and delegated output control is positive (+ 0.431) and statistically significant, confirming $\mathrm{H} 3$ Contingency.

Overall, the congruence form of fit receives no support in any of the three societies. The contingency form of fit finds support in two out of the three societies. Only for Central Europe do we observe no form of fit with MCSs. From a contingency perspective the opposite findings regarding the congruence and contingency forms of fit in Anglo-Saxon and the Northern European societies should be no surprise. If institutional differences across societies are moderate, organizational adaptation may not differ radically between societies even though some organizational structures and controls may be more advantageous in one society than in others.

Recall that all the hypotheses are formulated in relative terms. The congruence hypotheses are tested by comparing the closeness to an ideal MCS between societies. For example, the results of the test of $\mathrm{H} 1_{\text {Congruence }}$ indicate that Anglo-Saxon firms in general are more distant from the programmable output control type than are firms in the two other societies. This result does not suggest that programmable output control is discarded by Anglo Saxon firms; it suggests only that this sort of MCS is even more popular among firms in other societies. To capture the use of MCSs we assess the mean value of closeness (i.e. reversed distances) to each ideal MCS in each society. Results are displayed in Table 8.

Table 8 about here

A high value indicates closeness to an ideal MCS. The same MCS leads in all three groups, namely the delegated bureaucratic control system. Only in Central European society is this control system expected to dominate. The results presented in Table 8 provide information pertaining to how firms in the three societies position themselves regarding MCSs but they do not alter our previous conclusions about adaptation - the congruence form of fit receives very little support in this study.

How sensitive are the results to the assumptions made when the modified typology was quantified? Recall that the dimension of influence (of subordinates) in the delegated control system in Whitley (1999a) is set to "medium", but since no other group is rated higher on this item 
"medium" may as well be considered the maximum rate. In this study we decided to translate "medium" with the number 4 on a 7-graded scale, but how would the results have been affected if "medium" for influence were translated to 7 ? We adjusted the values for influence in delegated bureaucratic control and delegated output control from 4 to 7 and reran the regressions. The resulting changes in coefficients were insignificant and the results from the hypothesis tests were not affected at all.

\section{Discussion}

The aim of this study was to investigate whether socio-cultural or societal institutions affect how companies design and use MCSs. Our ideas were based largely on Whitley (1999a) and Hotho (2014) and framed by the contingency theory view of structural relations between contexts, MCSs, and effectiveness (Chenhall, 2003; Gerdin \& Greve, 2004). Specifically, the idea was to investigate whether certain types of MCSs dominate in certain societies (socio-cultural contexts) and whether the effectiveness of a given type of MCS varies depending on the sociocultural setting — the society—in which it operates

Business systems with unique characteristics evolve differently in distinct societies and when managers develop MCSs they are likely to adapt these systems to the business context in the societal context in which they operate. On this basis, Whitley (1999a) proposes that (programmable) output control dominates in the Anglo-Saxon group and that forms of delegated control dominate in the Central European and Northern European groups. The findings of this study, however, provide limited support for these propositions. We find that delegated forms of control prevail in the Central European and Northern European group, and that this also is the case for the Anglo-Saxon group. Our study suggests that there exists a subdivision of delegated control into delegated bureaucratic control and delegated output control. We hypothesize that the former type of delegated control should prevail in the Central European group and the latter type in the Northern European group. Our findings suggest that delegated bureaucratic control dominates in both the Central European and Northern European groups (and in the Anglo-Saxon group). In fact, the ranking of the three control systems is identical in the three institutional groups: delegated bureaucratic control ranks first, followed by delegated output control, and programmable output control. Thus, our study provides little support for the idea that certain types of MCS prevail in certain societies. 
The dominance of delegated bureaucratic control in our study does not necessarily, however, imply that this type of control has the most positive impact on organizational effectiveness in all institutional groups and as such it does not exclude that potential importance of societyMCS fit. Following Whitley's (1999a) arguments, we suggest that the adoption of an MCS that is compatible with the institutional context in which it operates has a more positive impact on effectiveness in the corresponding society compared with other societies where the MCS is incompatible. Because all the types of control included in this study exist in all three institutional groups, the study provides the opportunity to assess the relative effectiveness of the control systems in each group. Regarding the Anglo-Saxon and Northern European groups, our results clearly suggest that there is one control system that fits with an MCS in each society and that it is the predicted type of MCS that produces the results (H1 and H3). For the Central European group, however, delegated bureaucratic control (H2) has not had more positive effects on effectiveness than it has had in other societies.

To conclude, the findings in this study provide limited support for Whitley's (1999a) suggestion that MCSs adapt to the institutional contexts in which they operate. However, the idea that the effectiveness of MCSs varies across institutional contexts due to differences in societal institutions and business systems is largely supported (on two out of three societies/hypotheses). We find that programmable output control is more effective in the Anglo-Saxon group and that delegated output control is more effective in the Northern European group. Refining the types of MCSs in Whitley's (1999a) typology by subdividing delegated control into delegated bureaucratic control and delegated output control proved useful as it provides more highly detailed insights and enables us to draw more refined conclusions about MCSs in institutional contexts. As such our results lend support to the relevance of Whitley's societal institutional perspective on business systems to the understanding of the design and effectiveness of MCSs in a crosssocietal comparative perspective. To the best of our knowledge, few tests have been performed to test the predictive validity of existing typologies. Another addition to the business system literature is that we provide further support for Hotho's (2014) notion that Northern European countries mix liberal influences from Anglo-Saxon countries with corporate influences from Central Europe into a particular institutional context that bears consequences for MCS effectiveness.

These results of our study also contributes to two important and somewhat interwoven discussions within management accounting research. First, our findings contribute to the contingency theory literature (Chenhall, 2003) by adding a novel contingency factor that is important for 
explaining the appropriateness of certain types of MCS depending on context. Apart from contingencies at the firm level, we show that society is a factor that determines the appropriateness of MCS design. To the best of our knowledge this is one of the first large-scale studies to provide evidence of such an effect. Our approach to detecting the importance of society-MCS fit has been to interact three types of MCS with society — while controlling for firm-specific contingencies - to assess the importance of society-MCS fit. Future research efforts could, however, be directed at developing theoretical and empirical approaches to assess potential interactions between society, firm-specific contingencies, and MCSs. Such an approach would imply theorizing cross-level interactions (Luft \& Shields, 2003) and using multi-level statistical modeling.

Concerning the forms of fit deduced from Whitley's framework and contingency theory, our study suggests that the adaptation process results not in congruence but in a contingent explanation (Gerdin \& Greve, 2004). Certain MCSs do not dominate in certain societies, but their effectiveness differs. As developed above it is natural to find support for the contingency form of fit, where the congruence form of fit is not present (or vice versa), if the underlying theory of fit is valid. So, in that sense the rejection of the hypotheses based on the congruence form of fit does not imply a weakening of the general theory of fit, which is the subject matter of contingency theory (Donaldson, 2001). Rather, it indicates that the societies under investigation share components (overlap) that make it possible for multiple MCS designs to be in use, but at same time the societies are distinctly different in a way that makes certain MCS designs more appropriate. Considering that the societies that have been available for analysis for this research are all located in the Western world and therefore to some extent share a business system institutional origin, perhaps comparisons with other and more dissimilar societies (Asia and Africa) would also lend support to the idea that certain MCSs dominate in certain societies.

Second, our study contributes to the literature discussing the notion of a global convergence of MCS practices (Brandau et al., 2013; Lukka \& Granlund, 1998; Van der Stede, 2003). Due to isomorphic pressures (DiMaggio and Powell, 1983) stemming from e.g. intracorporate structures, professionalization and mimicry, and rationalized myths (Meyer and Rowan, 1977) about MCS practices, certain practices spread and stick (Colyvas \& Jonsson, 2011) in organizational fields, and hence local variants (adaptations) of practices tend to disappear over time. Our results suggest that such processes are influencing the adoption and design of MCS practices in our cross-society sample since we find little support for the notion of the popular domination 
of certain MCSs in certain societies. A theoretical explanation for such a finding is most probably related to the convergence of MCSs across societies. Importantly, we contribute to this line of research by showing that, while MCS convergence is most likely at stake here, the convergence, or homogenization, at the wider business system level (the institutional arrangement) has not been exhaustive and as such the appropriateness of certain types of MCSs remains bound to local settings. While the MCS types investigated here all have a similar spread, certain MCSs are more appropriate in certain societies, which is explained by the separately evolved business systems in these societies. In that sense it could be argued that institutional theory of convergence and the contingency theory of society-MCS fit complement each other.

This study has several implications for the contingency framework. First, society represents a contextual factor that influences the effectiveness of MCS. This is important when we compare particular designs of MCSs across societies to judge which are most effective. Prior inter-societal studies have typically explained observed differences by reference to national culture (e.g. Harrison, 1992; Merchant et. al., 1995) but the results have been mixed (Chenhall, 2003). The addition of institutional factors may produce more robust results in such studies. Second, society represents a contextual factor at a higher system level than has usually been applied in contingency studies. This should have implications for our interpretation of reported findings in contingency studies. Societal factors may have direct effects on the effectiveness of an MCS (as demonstrated in the present study) or they may have indirect effects (when they influence how contingencies on an organizational level affect the effectiveness of an MCS). In both cases the observed effects of MCSs are circumscribed by the societal context in which the study has taken place. Historically, many contingency studies have been carried out in Anglo-Saxon countries and the contemporary contingency framework may thus be biased towards this societal type. One practical implication should also be mentioned. When firms expand and go abroad they should remember that the effectiveness of an MCS depends on institutional factors in the society where the MCS is deployed. Therefore, it may be more profitable to develop control systems that fit with local institutions than to export the same MCS to all foreign units.

Our study is not without limitations. Although we used an interview-based survey approach our data collection method still potentially suffers from the general weakness of using subjective ratings from one respondent as information pertaining to an entire organization (SBU). The Anglo-Saxon group of countries in this study was represented only by Australia and Canada. This might limit the reliability of our results. Therefore, future studies could replicate (or extend) our study with a greater number of Anglo-Saxon countries. Furthermore, the typology of 
institutional contexts used in this study comprises institutional groups that are quite similar in characteristics, particularly in their high trust in formal institutions and reliance on contractbased relations of authority. Future research could therefore examine relationships between institutional contexts and MCSs using an extended typology which includes institutional groups that differ even more widely on these (and other) characteristics. Clustering countries in rather crisp types of societies (Hotho, 2014) may hide interesting nuances that could either strengthen or weaken the results found here. Factoring fuzzier nuances of difference between regions in different countries and across societies might also be interesting. 


\section{References}

Abrahamson, E. (1991). Managerial fads and fashions: The diffusion and rejection of innovations, The Academy of Management Review, 16, 586-612.

Abernethy, M. A. \& Brownell, P. (1997). Management control systems in research and development organizations: the role of accounting, behavior and personnel controls, Accounting, Organizations and Society, 22, 233-248.

Adler, P., S. \& Borys, B. (1996). Two types of bureaucracy: Enabling and coercive, Administrative Science Quarterly, 41, 61-89.

Anthony, R. N. \& Govindarajan, V. (1995). Management control systems, $8^{\text {th }}$ edition, Boston, Massachusetts: Irwin McGraw-Hill.

Bagozzi, R. P., Yi, Y. \& Phillips, L. W. (1991). Assessing construct validity in organizational research. Administrative Science Quarterly 36, 421-458.

Bedford, D. \& Malmi, T. (2015). Configurations of control: an exploratory analysis, Management Accounting Research, 27, 2-26.

Bhimani, A. (1999). Mapping methodological frontiers in cross-national management control research. Accounting Organizations and Society, 24, 413-440.

Bhimani, A. (2007). Comparative management accounting research: past forays and emerging frontiers, In Chapman, C.S., Hopwood, A. G., Shields, M., D. (Eds.) Handbook of management accounting research Vol. 1 (pp. 343-363). Oxford: Elsevier.

Bogsnes, B. (2009). Implementing beyond budgeting: unlocking the performance potential. Hoboken, New Jersey: John Wiley \& Sons.

Brandau, M., Endenich, C, Trapp, R. \& Hoffjan, A. (2013). Institutional drivers of conformity: evidence from management accounting from Brazil and Germany, International Business Review, 22, 466-479.

Casper, S. \& Whitley, R. (2004). Managing competences in entrepreneurial technology firms: a comparative institutional analysis of Germany, Sweden and the UK, Research Policy, 33, 89106.

Chenhall, R. H. (2003). Management control systems design within its organizational context: findings from contingency-based research and directions for the future, Accounting, Organizations and Society, 28, 127-168.

Chenhall, R.H. \& Langfield-Smith, K. (1998). The relationship between strategic priorities, management techniques and management accounting: an empirical investigation using a system approach, Accounting, Organizations and Society, 23, 243-264.

Cochran, W. G. (1977). Sampling techniques. 3. New York: Wiley

Colyvas, J.A. \& Jonsson, S. (2011). Ubiguity and legitimacy: disentangling diffusion and institutionalization, Sociological Theory, 29, 27-53 
DiMaggio, P.J. \& Powell, W.W. (1983). The iron cage revisited: institutional isomorphism and collective rationality in organizational fields, American Sociological Review, 48, 147-160.

Donaldson, L. (2001). The contingency theory of organizations. Thousand Oaks, CA: Sage Publications.

Doty, D. H. \& Glick, W. H. (1994). Typologies as a unique form of theory building: toward improved understanding and modeling, Academy of Management Review, 19, 230-251.

Doty, D.H., Glick, W.H. \& Huber, G.P. (1993). Fit, equifinality, and organizational effectiveness: a test of two configurational theories, Academy of Managerial Journal, 36, 1196-1250.

Drazin, R. \& Van der Ven, A. H. (1985). Alternative forms of fit in contingency theory, Administrative Science Quarterly, 30, 514-539.

Eisenhardt, K. M. (1985). Control: organizational and economic approaches, Management Science, 31 (2). 134-149.

Emmanuel, C., Otley, D. \& Merchant, K. (1996). Accounting for management control. $2^{\text {nd }}$ edition. Cornwall: International Thomson Business Press.

Gerdin, J. \& Greve, J. (2004). Forms of fit in management accounting research - a critical review, Accounting, Organizations and Society, 29, 303-326.

Gordon, L. A. \& Miller, D. (1976). A contingency framework of the design of accounting information systems, Accounting, Organizations and Society, 1, 56-69.

Govindarajan, V. (1984). Appropriateness of accounting data in performance evaluation: an empirical examination of environmental uncertainty as an intervening variable, Accounting, Organizations and Society, 9, 125-135.

Govindarajan, V. \& Fisher, J. (1990). Strategy, control systems, and resource sharing: effects on business-unit performance, Academy of Management Journal, 33, 259-285.

Govindarajan, V. \& Gupta, A. (1985). Linking control systems to business unit strategy: Impact on performance. Accounting Organizations and Society, 10 (1), 51-66.

Grabner, I. \& Moers, F. (2013). Management control as a system or a package. Conceptual and empirical issues, Accounting, Organizations, and Society, 38, 407-419.

Hair J. F., Jr., Anderson, R. E., Tatham, R. L. \& W. C. Black. (2010). Multivariate Data Analysis. Englewood Cliffs. NJ: Prentice Hall.

Halvorsen, T., Korsnes, O. \& Sakslind, R. (1996). The Norwegian disconnection: professional unity and industrial division. In Whitley, R. \& Kristensen, P., H. (Eds.). The changing European firm. Limits to converse (pp. 305-328). London: Routledge. 
Harrison, G. L. (1992). The cross-cultural generalizability of the relation between participation, budget emphasis and job-related attitudes. Accounting, Organizations and Society, 17, 1-15.

Hartmann, F. G. H. (2000). Studying the role of accounting in performance evaluation - The appropriateness of RAPM: toward the further development of theory, Accounting, Organizations and Society, 25, 451-482.

Hartmann, F. G. H. \& Moers, F. (1999). Testing contingency hypotheses in budgetary research: an evaluation of the moderated regression analysis, Accounting, Organizations and Society, 24, 291-315.

Hartzing, A-W. \& Sorge, A. (2003). The relative impact of country of origin and universal contingencies on internalization strategies and corporate control in multinational enterprises: Worldwide and European perspectives, Organization Studies, 24, 187-214.

Henri, J-F. (2006). Management control systems and strategy: a resource-based perspective, Accounting, Organizations and Society, 31, 529-558.

Hotho, J.J. (2014). From typology to taxonomy: a configurational analysis of national business systems and their explanatory power, Organization Studies, 35 (5). 671-702.

Johansson, T. (2015). A critical appraisal of the current use of transaction cost explanations for government make-or-buy choices: towards a contingent theory and forms of tests, Public Management Review, 17, 661-678.

Khandwalla, P.N. (1977). The design of organizations, New York, Jovanovich.

Kristensen, P.H. \& Morgan, G. (2012). From institutional change to experimentalist institutions, Industrial Relations, 51, 413- 437.

Kruis, A.-M., Speklé, R. F. \& Widener, S. K. (2016). The levers of control framework: an exploratory analysis of balance. Management Accounting Research, 32, 27-44.

Lane, C. (1997). The governance of interfirm relations in Britain and Germany: societal or dominance effects? In Whitley, R., \& Kristensen, P., H. (Eds.) Governance at work (pp. 6285). New York: Oxford University Press

Lane, C. (2006). European companies between globalization and localization: a comparison of internationalization strategies of British and German MNCs, Economy and Society, 27:4, 462485 .

Lebas, M. \& Weigenstein, J. (1986). Management control: the roles of rules, markets and culture, Journal of Management Studies, 23, 259-272.

Lilja, K. \& Tainio, R. (1996). The nature of the typical Finnish firm. In Whitley, R. \& Kristensen, P., H. (Eds.). The changing European firm. Limits to converse (pp. 159-191). London: Routledge.

Luft, J. \& Shields, M. D. (2003). Mapping management accounting: graphics and guidelines for theory-consistent empirical research, Accounting, Organizations and Society, 28, 169-249. 
Lukka, K. \& Granlund, M. (1998). It's a small world of management accounting practices, Journal of Management Accounting, 10, 153-179.

Malmi, T. \& Brown, D. A. (2008). Management control systems as a package - opportunities, challenges and research directions, Management Accounting Research, 19, 287-300.

Maurice, M. (1979). For a study of 'the societal effect': universality and specificity in organization research. In Lammers C. J., \& Hickson, D. J (Eds.). Organizations alike and unlike. International and inter-institutional studies in the sociology of organization (pp. 42-60). London: Routledge \& KeeganPaul Ltd.

Merchant, K., Chow, C. W. \& Wu, A. (1995). Measurement, evaluation and reward of profit center managers: a cross sectional field study. Accounting, Organizations and Society, 20, 619638 .

Merchant, K. A. \& Van der Stede, W. A. (2013). Management Control Systems. Performance Measurement, Evaluations and Incentives. $3^{\text {rd }}$ edition, Essex: Prentice Hall.

Meyer, J.W. \& Rowan, B. (1977). Institutionalized organizations: formal structure as myth and ceremony, American Journal of Sociology, 83, 340-363.

Miller, D. \& Friesen, P.H. (1983). Strategy-making and environment: the third link, Strategic Management Journal, 4, 221-235.

Mintzberg, H. (1983). Structures in fives: Designing effective organizations, Englewood Cliffs, NJ: Prentice Hall.

Morgan, G. (2009). Globalization, multinationals and institutional diversity, Economy and Society, 38, 580-605.

North D. C. (1991). Institutions, The journal of economic perspectives, 5, 97-112.

Ouchi, W. G. (1977). The relationship between organizational structure and organizational control, Administrative Science Quarterly, 22 (1). 95-113.

Ouchi, W. G. (1979). A conceptual framework for the design of organizational control mechanisms, Management Science, 25 (9). 833- 849.

Ouchi, W. G. (1980). Markets, bureaucracies and clans, Administrative Science Quarterly, 25, 129-141.

Rockness, H. O. \& Shield, M. D. (1984). Organizational control systems in research and development, Accounting, Organizations and Society, 9, 165-177.

Räsänen, K. \& Whipp, R. (1992). National business recipes: a sector perspective. In R. Whitley (Ed.) European business systems (pp. 46-60). London: Sage.

Schaffer, B. S. \& Riordan, C. A. (2003). A review of cross-cultural methodologies for organizational research: a best practices approach. Organizational Research Methods 6 (2). 169-215. 
Shields, J. F. \& Shields, M. D. (1998). Antecedents of participative budgeting, Accounting, Organizations and Society, 23, 49-76.

Simons, R. (1995). Levers of control. How managers use innovative control systems to drive strategic renewal. Boston, Massachusetts: Harvard Business School Press.

Simons, R. (2005). Levers of organization design, How managers use accountability systems for greater performance and commitment, Boston, Massachusetts: Harvard Business School Press.

Snell, S. A. (1992). Control theory in strategic human resource management: the mediating effect of administrative information, The Academy of Management Journal, 35, 292-327.

Sorge, A. (1991). Strategic fit and the societal effect: interpreting cross-national comparisons of technology, organization and human recourses, Organization Studies, 12, 161-190.

Sorge, A. \& Maurice, M. (1993). The societal effect in the strategies of French and West German machine tool manufacturers. In B. Kogut (Ed.) Country competitiveness: technology and the organization of work (pp. 75-95). Oxford: Oxford University Press.

Sorge, A. \& Warner, M. (1986). Comparative factory organization. An Anglo-German Comparization of management and manpower in manufacturing, Hants, UK: Gover.

Speklé, R. F. (2001). Explaining management control structure variety: a transaction cost economics perspective, Accounting, Organizations and Society, 26, 419-441.

Van der Meer-Koistra, J. \& Vosselman, E. G. J. (2000). Management control of interfirm transactional relationships: the case of industrial renovation and maintenance. Accounting, Organizations \& Society, 25 (1). 51-77.

Van der Stede, W. A. (2001). Measuring 'tight budgetary control', Management Accounting Research, 12, 119-137.

Van der Stede, W.A. (2003). The effect of national culture on management control and incentive system design in multi-business firms: evidence of intracorporate isomorphism, European Accounting Review, 12, 263-285.

Van Iterson, A. (1996). Institutions and types of firms in Belgium: regional and sectoral variations. In Whitley, R. \& Kristensen, P. H. (eds). The changing European firm. Limits to convergence (pp. 192-209). London: Routledge.

Whitley, R. (1992). Societies, firms and markets: the social structuring of business systems. In R. Whitley (Ed.) European Business Systems (pp. 5-45). London: Sage.

Whitley, R. (1999a). Firms, institutions and management control: The comparative analysis of coordination and control systems. Accounting, Organizations and Society, 24, 507-524.

Whitley, R. (1999b). Divergent capitalisms: the social structuring and change of business systems, Oxford: Oxford University Press. 
Whitley, R. (2000). The institutional structuring of innovation strategies: business systems, firm types and patterns of technical change in different market economies, Organization Studies, 21, 855-886.

Whitley, R. (2002). Developing innovative competences: the role of institutional frameworks, Industrial and Corporate Change, 11, 497-528.

Whitley, R. (2006). Understanding differences: searching for the social processes that construct and reproduce variety in science and economic organization, Organizations Studies, 27 (8), 1153-1177.

Widener, S. (2007). An empirical analysis of the levers of control framework, Accounting, Organizations and Society, 32, 757-788.

Williamson, O.E. (1985). The economic institutions of capitalism. Firms, markets, relational contracting, New York, NY: The Free Press.

Williamson O. E. (1998). Transaction cost economics: how it works; where it is headed, The Economist, 146, 23-58. 


\section{Appendix 1. Questionnaire items}

Formality (7-graded scales)

To what extent do members of the SBU's top management team use budgets and/or performance measures for the following:

a) Identify critical performance variables (i.e. factors indicating progress towards strategic objectives)

b) Set targets for critical performance variables

c) Monitor progress towards and correct deviations from preset performance targets.

\section{Activity control (7-graded scales)}

In trying to guide and control your subordinate's behavior, how extensively do you. . .

a) Use company-wide codes of conduct or similar statements?

b) Segregate duties and review plans before actions?

c) Employ written authorization levels and decision rules?

d) Make sanctions of unethical businesses known to subordinates (e.g. by written statements)?

e) Employ written guidelines that stipulate specific areas for, or limits on, opportunity search and experimentation?

f) Actively communicate in writing the risks and activities to be avoided by subordinates?

g) Apply sanctions to subordinates who engage in risks outside organizational policy, irrespective of the outcome?

\section{Influence}

Please indicate, by checking one box in each column, which alternative best describes short-term target setting.

ENDS

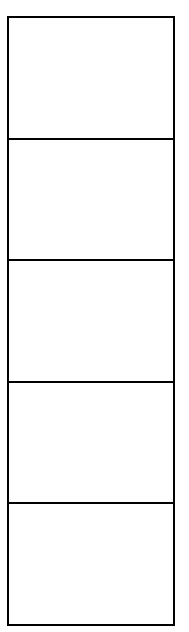

MEANS

1. Top management sets targets and passes them to subordinates

2. Top management sets targets, but revises them in negotiations with subordinates

3. Targets setting is quite long, iterative negotiation process between organizational levels

4. Subordinates set autonomously targets, but they are subject to top management acceptance

5. Subordinates set targets autonomously with little, if any, management involvement

Scope (7-graded scales)

Please indicate to what extent you base your subordinates' performance on
a) Achievements in leadership behaviour
b) Actions and activities taken
c) Individual effort

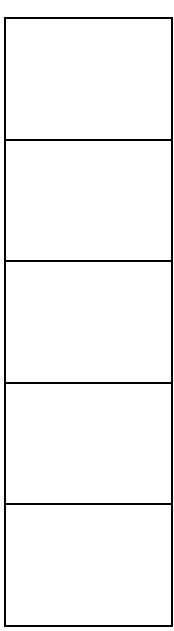




\section{Appendix 2. Statistics of measurement analysis}

Confirmatory factor analysis (maximum likelihood). Factors loadings and latent variable correlations.

Correlations

Formality (CR 0.840)

Budgets for identification of critical measures

Budget for targeting

Budgets for monitoring

Activity control (CR 0.759)

Codes of conduct

Authorization levels

Sanctions of unethical conduct

Communicate activities to be avoided

Sanctions for engaging in risks outside policy

Influence (CR 0.649)

How are short-term targets set regarding ends

How are short-term targets set regarding means

Scope (CR 0.704)

Evaluations of leadership

Evaluations of actions taken

Evaluations of individual effort

Loadings
$0.778^{* * *}$
$0.853^{* * *}$
$0.760^{* * *}$

Activity Influence Scope

$0.245^{* * *}$

$-0.127 *$

0.152 **

$0.760 * * *$

$-0.034$

$0.403^{* * *}$

$0.617 * * *$

$0.628 * * *$

$0.527 * * *$

$0.677 * * *$

$0.653^{* * *}$

$-0.031$

$0.753 * * *$

$0.630 * * *$

$0.663^{* * * *}$

$0.673 * * *$

$0.658 * * *$

Model fit: $X^{2}$ 151.904***; Df 60; CFI 0.954; TLI 0.940; RMSEA 0.050 (Pclose 0.473). CR means composite reliability. $* * * \mathrm{p}<0.001 ; * * \mathrm{p}<0.01 ; * \mathrm{p}<0.05$.

For the Influence construct we assumed equal weighting of items since a factor structure with less than three indicators is under identified in isolation and may produce meaningless weights (above 1) even when included in a nomological network. To test for discriminant validity we compared models where the correlation between constructs is set to 1 with models that estimates them freely (Bagozzi et al., 1991). In all instances the unconstraint models produced a statistically significant $(\mathrm{p}<.0 .05)$ lower chi-two value of one degree of freedom difference, showing that they discriminate. Also the latent variable correlations indicate that they are only moderately correlated with each other. The highest correlation $(r=0.403)$ is between Activity control and Scope. 
Table 1

Typology of societies (Sources: Whitley, 1999b; Hotho, 2014)

Institutional factors

Type 1

Type 2

Type 3

Compartmentalized

Collaborative

"New" type

Trust in formal institutions

High

High

High

Authority relations

Contract-based

Contract-based

Contract-based

Business dependence on the state

Low

Low

Considerable

Low

Extent of market regulations

Strength of training systems

Low

High

Low

Strength of unions

Low to some

High

High

High

High

Socio-cultural Groups

Anglo-Saxon

Central Europe

Northern Europe

Table 2

Typology of MCSs (Source: Whitley, 1999a, p. 511)

\begin{tabular}{lccc} 
& $\begin{array}{c}\text { Bureaucratic } \\
\text { control }\end{array}$ & $\begin{array}{c}\text { Output } \\
\text { control }\end{array}$ & $\begin{array}{c}\text { Delegated } \\
\text { control }\end{array}$ \\
\hline Reliance on formal rules & High & High & Mixed \\
Control of activities & High & Low & Low \\
Influence of subordinates & Low & Limited & Medium \\
Scope of control systems & Limited & Low & High
\end{tabular}

\section{Table 3}

A modified typology of MCS

\begin{tabular}{lcccc} 
& $\begin{array}{c}\text { Programmable } \\
\text { bureaucratic } \\
\text { control }\end{array}$ & $\begin{array}{c}\text { Programmable } \\
\text { output } \\
\text { control }\end{array}$ & $\begin{array}{c}\text { Delegated } \\
\text { bureaucratic } \\
\text { control }\end{array}$ & $\begin{array}{c}\text { Delegated } \\
\text { output } \\
\text { control }\end{array}$ \\
\hline Reliance on formal rules & High & High & High & High \\
Control of activities & High & Low & High & Low \\
Influence of subordinates & Low & Limited & Medium & Medium \\
Scope of control systems & Limited & Low & High & High
\end{tabular}

Table 4

Countries, numbers of SBUs, and titles of interviewees

Country Number of Percent of 


$\begin{array}{lrr} & \text { SBUs } & \text { SBUs } \\ \text { Australia } & 38 & 6.2 \\ \text { Austria } & 36 & 5.9 \\ \text { Belgium } & 43 & 7.0 \\ \text { Canada } & 45 & 7.4 \\ \text { Denmark } & 111 & 18.2 \\ \text { Finland } & 94 & 15.4 \\ \text { Germany } & 78 & 12.8 \\ \text { Norway } & 63 & 10.3 \\ \text { Sweden } & 102 & 16.7 \\ \text { Total } & 610 & 100.0\end{array}$

Title of interviewee

$\begin{array}{lrr}\text { CEO } & 199 & 32.6 \\ \text { CFO } & 247 & 40.5 \\ \text { COO } & 28 & 4.6 \\ \text { Other } & 125 & 20.5 \\ \text { N/A } & 11 & 1.8 \\ \text { Total } & 610 & 100.0\end{array}$

Table 5

Typology of MCSs on a 1-7 scale

$\begin{array}{lccc}\begin{array}{c}\text { Programmable } \\ \text { output } \\ \text { control }\end{array} & \begin{array}{c}\text { Delegated } \\ \text { bureaucratic } \\ \text { control }\end{array} & \begin{array}{c}\text { Delegated } \\ \text { output } \\ \text { control }\end{array} \\ \text { Formalization } & 7 & 7 & 7 \\ \text { Activity control } & 1 & 7 & 1 \\ \text { Influence } & 2 & 4 & 4 \\ \text { Scope } & 1 & 7 & 7\end{array}$


Table 6

Descriptive statistics ( $\mathrm{N}=610)$

\begin{tabular}{lrrrr} 
& Mean & \multicolumn{1}{l}{ Min } & \multicolumn{1}{l}{ Max } & Std. Dev. \\
ROA & 0.080 & -0.530 & 0.890 & 0.121 \\
Programmed output & 5.975 & 1.270 & 10.490 & 1.316 \\
Delegated bureaucrat. & 7.670 & 2.140 & 11.400 & 1.574 \\
Delegated output & 6.723 & 2.300 & 10.080 & 1.193 \\
Anglo-Saxon & 0.136 & 0.000 & 1.000 & 0.343 \\
Central Europe & 0.257 & 0.000 & 1.000 & 0.438 \\
Northern Europe & 0.607 & 0.000 & 1.000 & 0.489 \\
Dynamism & 3.964 & 1.000 & 6.170 & 0.902 \\
Unpredictability & 3.643 & 1.170 & 6.330 & 0.842 \\
Complexity & 3.810 & 1.000 & 7.000 & 1.280 \\
Hostility & 4.781 & 1.000 & 7.000 & 1.005 \\
Industry_service & 0.395 & 0.000 & 1.000 & 0.489 \\
Industry_trade & 0.139 & 0.000 & 1.000 & 0.347
\end{tabular}

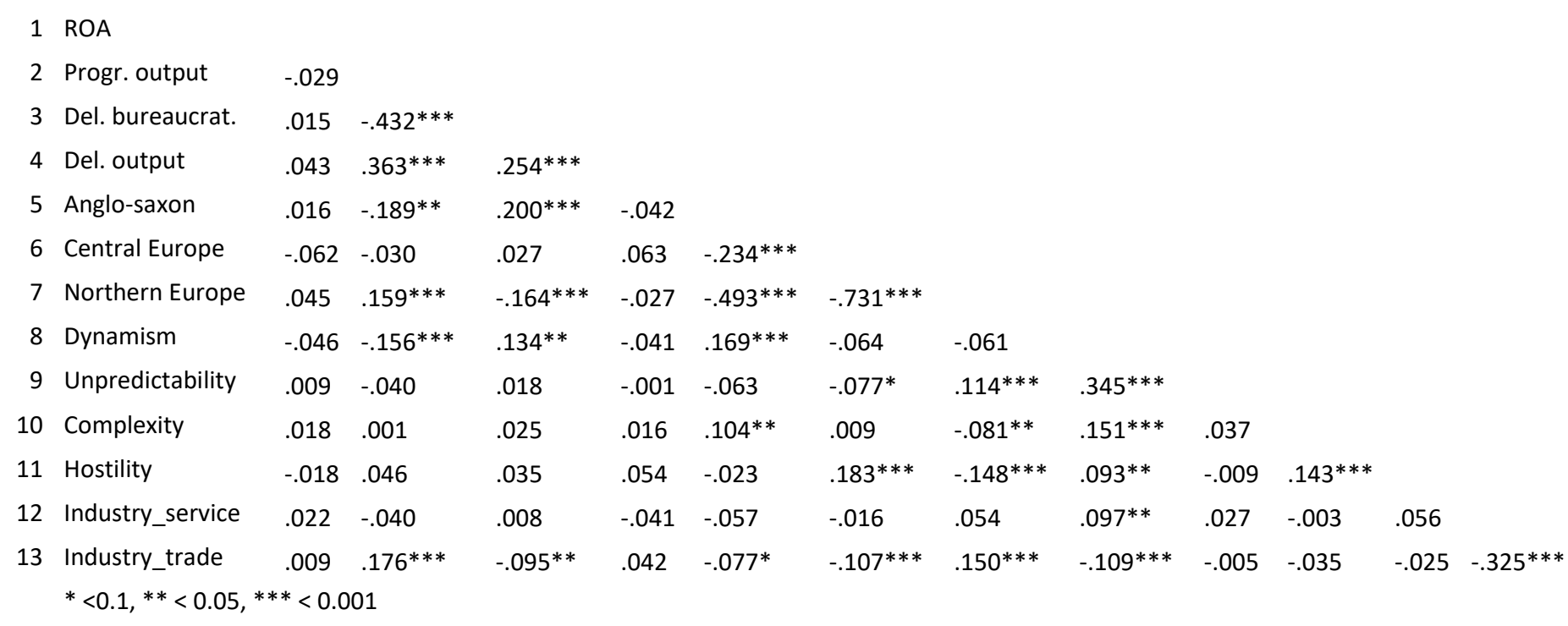


Table 7

Results of OLS regressions of congruence form fit and contingency form of fit $(\mathrm{N}=610)$

\begin{tabular}{|c|c|c|c|c|c|c|}
\hline & \multicolumn{2}{|c|}{ Anglo-Saxon } & \multicolumn{2}{|c|}{ Central Europe } & \multicolumn{2}{|c|}{ Northern Europe } \\
\hline & $\mathrm{H} 1_{\text {congruence }}$ & $\mathrm{H} 1_{\text {contingency }}$ & $\mathrm{H} 2$ congruence & $\mathrm{H} 2$ contingency & $\mathrm{H} 3_{\text {congruence }}$ & $\mathrm{H} 3_{\text {contingency }}$ \\
\hline Anglo-Saxon & $-0.159 * * *$ & $-0.481 * *$ & & & & \\
\hline Program. output control & & -0.062 & & & & \\
\hline Anglo x Program Output & & $0.508^{* *}$ & & & & \\
\hline Central Europe & & & 0.020 & 0.064 & & \\
\hline Del. bureaucratic control & & & & 0.037 & & \\
\hline Central x Del. Bureaucratic & & & & -0.130 & & \\
\hline Northern Europe & & & & & -0.026 & -0.379 \\
\hline Delegated output control & & & & & & -0.050 \\
\hline Northern x Del. Output & & & & & & $0.431 *$ \\
\hline \multicolumn{7}{|l|}{ Control variables } \\
\hline Dynamism & $-0.120 * * *$ & -0.068 & $0.136^{* * *}$ & -0.067 & -0.051 & -0.047 \\
\hline Complexity & 0.034 & 0.034 & 0.000 & 0.027 & 0.014 & 0.029 \\
\hline Unpredictability & -0.009 & 0.031 & -0.027 & 0.023 & 0.020 & 0.017 \\
\hline Hostility & 0.052 & -0.014 & 0.018 & -0.007 & 0.056 & -0.019 \\
\hline Industry_1 & 0.011 & 0.036 & -0.034 & 0.031 & -0.027 & 0.034 \\
\hline Industry_2 & 0.156 & 0.021 & $-0.089 * *$ & 0.009 & 0.034 & 0.011 \\
\hline Dependent variable & $\begin{array}{c}\text { Program. } \\
\text { output } \\
\text { control }\end{array}$ & ROA & $\begin{array}{c}\text { Delegated } \\
\text { bureaucratic } \\
\text { control }\end{array}$ & ROA & $\begin{array}{c}\text { Delegated } \\
\text { output } \\
\text { control }\end{array}$ & ROA \\
\hline
\end{tabular}

${ }^{*} p<0.1,{ }^{* *} p<0.05, * * * p<0.01$ (two-tailed)

Table 8

Mean Euclidian distance (reversed) to each of three MCS types $(\mathrm{N}=610)$

$\begin{array}{lccc} & \text { Anglo- } & \text { Central } & \text { Northern } \\ & \text { Saxon } & \text { European } & \text { European } \\ & \text { group } & \text { group } & \text { group } \\ & \mathrm{N}=83 & \mathrm{~N}=157 & \mathrm{~N}=370 \\ \text { 1. Programmable output control } & 5.350 & 5.908 & 6.144 \\ \text { 2. Delegated bureaucratic control } & 8.464 & 7.742 & 7.462 \\ \text { 3. Delegated output control } & 6.596 & 6.851 & 6.697 \\ \text { Ranking }^{\text {a }} & 2<3<1 & 2<3<1 & 2<3<1\end{array}$

a) Paired-samples t-test $(p<0,001)$ 
Figure 1

Two forms of fit

Table A Congruence form of fit

\begin{tabular}{c|c} 
Societal \\
institutions
\end{tabular}$\longrightarrow$ MCS

Table B Contingency form of fit

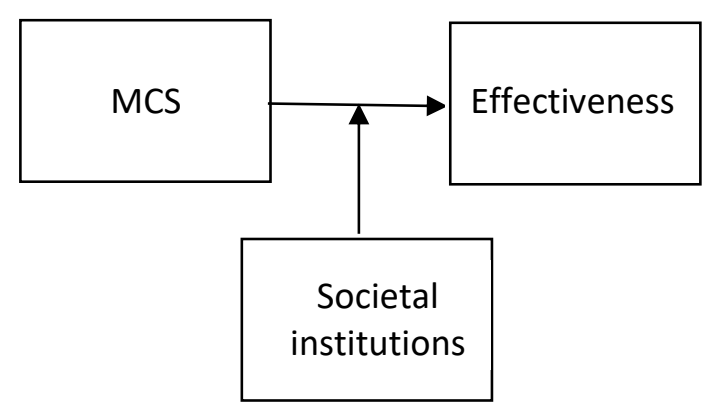

